\title{
Erratum to: Mucinous Tumor of the Appendix with Limited Peritoneal Spread: Is There a Role for Expectant Observation?
}

Francis S. W. Zih, MD, MSc ${ }^{1}$, Nathalie Wong-Chong, BHSc, MD ${ }^{1}$, Claire Hummel, $\mathbf{R N}^{1}$, Jennifer Petronis, $\mathbf{R N}^{\mathbf{2}}$, Tony Panzarella, BSc, MSc ${ }^{3}$, Aaron Pollett, $\mathrm{MD}^{4}$, J. Andrea McCart, MD, MSc, FRCSC ${ }^{1}$, and Carol J. Swallow, MD, PhD, FRCSC, FACS ${ }^{1}$

${ }^{1}$ Department of Surgical Oncology, Mount Sinai and Princess Margaret Hospitals, Toronto, ON, Canada; ${ }^{2}$ Department of Radiation Oncology, Princess Margaret Hospital, Toronto, ON, Canada; ${ }^{3}$ Division of Biostatistics, Princess Margaret Hospital, Toronto, ON, Canada; ${ }^{4}$ Department of Pathology and Laboratory Medicine, Mount Sinai Hospital, Toronto, ON, Canada

ERRATUM TO: ANN SURG ONCOL

DOI 10.1245/S10434-013-3283-0

J. Andrea McCart's name is correct as presented in this erratum.

The online version of the original article can be found under doi:10. 1245/s10434-013-3283-0.

(C) Society of Surgical Oncology 2013

Published Online: 26 October 2013

F. S. W. Zih, MD, MSc

e-mail: francis.zih@gmail.com 